Artha-Journal of Social Sciences

2019, Vol. 18, No. 1, v-vii

ISSN 0975-329X| https:/ / doi: 10.12724/ajss.48.0

\title{
Editorial
}

\section{Women and Psychology}

The current issue of Artha-Journal of Social Sciences focusses on the theme - "women and psychology." The theme is congruent with feminist psychology which gives importance to women's behaviour and experiences within social contexts across their lives and advocates for change at the individual, organisational, and societal levels. Feminist psychology, in general, addresses topics such as health issues of women, stereotypes, development, perspectives on personality and mental health, sexuality, reproductive health and rights, verbal/nonverbal communications by/about women, intimate relationships, career psychology, women leadership, gender equity, violence against women, power, and social change (Denmark \& Paludi, 2016; Kalra \& Bhugra, 2013). Researchers in the field of feminist psychology serve as expert witnesses in court cases on issues such as sexual harassment, race discrimination, child sexual abuse, rape, and intimate partner violence (Denmark \& Paludi, 2016).

This issue of Artha-Journal of Social Sciences aims to address the inequality in social and institutional power between women and men. The issue has four manuscripts standing precisely with the theme, addressing the gender stereotypes, women's mental and physical health issues, career-related challenges, power and violence against women, and social change. In all these articles, an attempt is made to understand women as an individual within the broader political and social dimensions. Along with these, we have one exclusive manuscript on oral reading fluency among the learners of English as a second language.

The manuscript by Mythri Kukkaje reviews the current research in the understanding the studies on the perpetrators of violence against women. According to Kukkaje, social interventions currently designed to abolish the atrocities against women have emphasised on women empowerment. Kukkaje suggests that there should be specific action-oriented positive interventions for the 
perpetrators as well. However, that is problematised owing to the difficulty in locating the perpetrators. Hence, the intervention has to be initiated at the societal level.

Nida Hassain in her paper, Gender Biases and Discrimination While Hiring, presents how in the employment market gender equality is reinstated during the hiring process. Hassain argues that the discrimination prevails through implicit and in-group biases during hiring decisions. She recommends deliberate attempts to defuse gender stereotyping and suggests regular assessment and scrutiny of the hiring process to resolve the issue.

In the article, Cultural Variations in the Glass Ceiling Effect: A Review, Ragitha Radhakrishnan argues that gender disparity is universal. She writes about the phenomenon of Glass Ceiling, the barrier that prevents women from progressing to the higher positions in the organisations. Differences in pay and prevention of women from aspiring for higher level jobs are two significant consequences of the Glass Ceiling effect.

The manuscript by Sangeetha Thomas on Knowledge and Awareness about Diabestes Mellitus and Gestational Diabetes Mellitus - A Review, attracts our attention to Gestational Diabetes Mellitus (GDM) one of the critical physiological issues faced by pregnant women. Based on the review, she argues that understanding and orientation regarding GDM among the public is minimal. Hence, a lot of women have difficulty negotiating the organisational systems successfully. Education is a factor that contributes to the effective management of GDM. More studies on the knowledge and awareness about GDM could develop public health policies and specific health interventions.

Remya Rebecca Prakash and Abjy Kurian discuss the oral reading fluency while reading aloud in an accurate, rapid and expressive manner. Their findings indicate that oral reading fluency improves reading comprehension, and is helpful for the students with English as a second language.

\section{References}

Denmark, F., \& Paludi, M. (2016, May 31). Psychology of women. doi:10.1093/obo/9780199828340-0046 
Kalra, G., \& Bhugra, D. (2013). Sexual violence against women: understanding cross-cultural intersections. Indian Journal of Psychiatry, 55(3), 244-249. doi:10.4103/0019-5545.117139

Santhosh Kareepadath Rajan

Issue Editor 